\title{
Periostin facilitates eosinophil tissue infiltration in allergic lung and esophageal responses
}

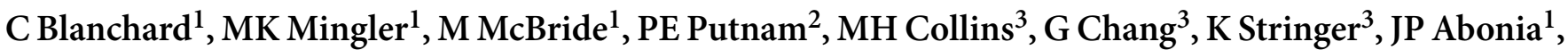 \\ JD Molkentin ${ }^{4}$ and ME Rothenberg ${ }^{1}$
}

Periostin is an extracellular matrix protein that has been primarily studied in the context of the heart, where it has been shown to promote cardiac repair and remodeling. In this study, we focused on the role of periostin in an allergic eosinophilic inflammatory disease (eosinophilic esophagitis (EE)) known to involve extensive tissue remodeling. Periostin was indeed markedly overexpressed (35-fold) in the esophagus of EE patients, particularly in the papillae, compared with control individuals. Periostin expression was downstream from transforming growth factor- $\beta$ and interleukin-13, as these cytokines were elevated in EE esophageal samples and markedly induced periostin production by primary esophageal fibroblasts (107- and 295 -fold, respectively, at $10 \mathrm{ng} \mathrm{ml}^{-1}$ ). A functional role for periostin in eliciting esophageal eosinophilia was demonstrated, as periostin-null mice had a specific defect in allergen-induced eosinophil recruitment to the lungs and esophagus (66 and $72 \%$ decrease, respectively). Mechanistic analyses revealed that periostin increased (5.8-fold) eosinophil adhesion to fibronectin. As such, these findings extend the involvement of periostin to esophagitis and uncover a novel role for periostin in directly regulating leukocyte (eosinophil) accumulation in T helper type 2-associated mucosal inflammation in both mice and humans.

\section{INTRODUCTION}

A common feature of both heart failure and inflammation is the occurrence of extensive tissue remodeling. ${ }^{1,2}$ Nearly all forms of heart failure involve remodeling of the extracellular matrix (ECM) and associated changes in ventricular geometry. ${ }^{2,3}$ Similarly, chronic inflammatory diseases involve extensive changes in tissue architecture, such as goblet cell metaplasia, airway wall thickening and increased airflow resistance in asthma, ${ }^{4}$ and tissue fibrosis in diseases such as eosinophilic esophagitis (EE).$^{5,6}$

Eosinophilic esophagitis is an emerging worldwide disease, as documented by recent case series from Switzerland, Australia, Israel, Italy, Spain, Japan, England, and the United States. ${ }^{7} \mathrm{EE}$ clinically mimics gastroesophageal reflux disease and can lead to esophageal fibrosis, narrowing, and stricture ${ }^{8}$ likely due to tissue remodeling that leads to impaired functional responses (e.g., motility). Murine models have established a role of T helper type 2 cytokines, especially interleukin (IL)-13, in EE development, as intratracheal instillation of IL-13 induces EE in mice. ${ }^{9,10}$ In humans, preliminary investigations have suggested that circulating T cells and eosinophils from EE patients overproduce IL-13, ${ }^{11,12}$ and IL-13 is markedly overproduced in esophageal tissue of EE patients; in addition, IL-13 is able to induce an EE-like transcriptome in primary esophageal epithelial cell cultures. ${ }^{13}$ Moreover, transforming growth factor- $\beta$ (TGF $\beta$ ), a cytokine involved in tissue fibrosis, and its signaling molecules SMAD-2/3 have been shown to be overexpressed in EE esophageal biopsies. ${ }^{5}$ Based on genome-wide microarray transcript profile analysis of esophageal tissue, several IL-13-induced genes have been demonstrated to be increased in $\mathrm{EE}$ (such as eotaxin-3 and IL-13 receptor alpha2). ${ }^{14}$ Among these genes, periostin has attracted our attention, as very recent studies have shown that periostin is involved in remodeling and repair responses in the heart. Furthermore, it is induced in T helper type 2-associated responses in the lung, although a role in this response has not been shown. ${ }^{3,15,16}$

\footnotetext{
${ }^{1}$ Division of Allergy and Immunology, Department of Pediatrics, Cincinnati Children's Hospital Medical Center, University of Cincinnati College of Medicine, Cincinnati, Ohio, USA. Division of Gastroenterology, Hepatology, and Nutrition, Department of Pediatrics, Cincinnati Children's Hospital Medical Center, University of Cincinnati College of Medicine, Cincinnati, Ohio, USA. ²Division of Pathology and Laboratory Medicine, Department of Pediatrics, Cincinnati Children's Hospital Medical Center, University of Cincinnati College of Medicine, Cincinnati, Ohio, USA. ${ }^{4}$ Division of Molecular Cardiology, Department of Pediatrics, Cincinnati Children's Hospital Medical Center, University of Cincinnati College of Medicine, Cincinnati, Ohio, USA. Correspondence: ME Rothenberg (Rothenberg@cchmc.org) 

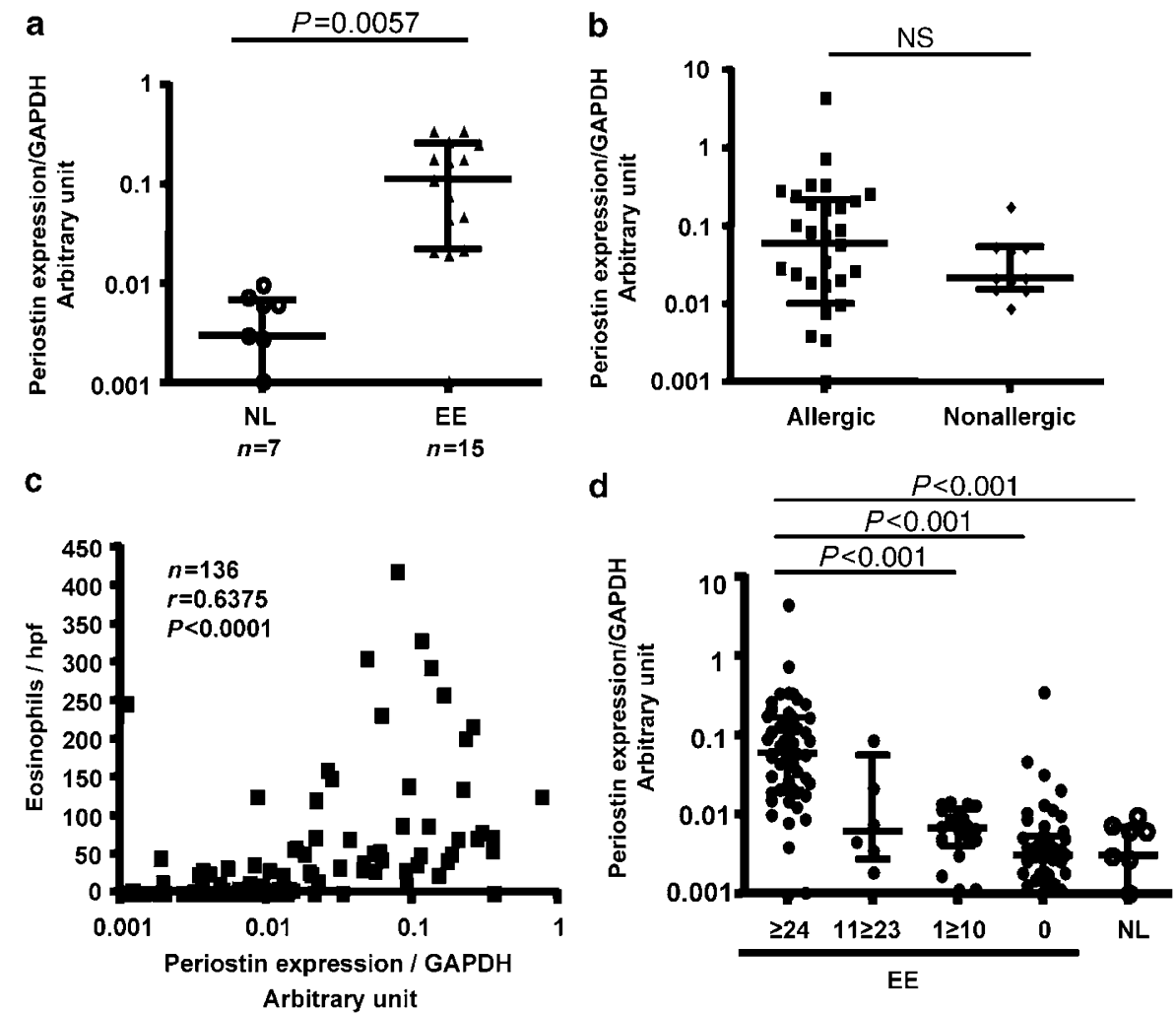

Figure 1 Analysis of periostin expression mRNA in the esophageal mucosa of normal individuals and eosinophilic esophagitis (EE) patients and correlation with eosinophil level. (a) Periostin mRNA expression was quantified in esophageal biopsies of normal (NL) individuals and untreated EE patients. (b) Active EE patients with $\geqslant 24$ eosinophils/hpf were separated into allergic and non-allergic EE patients. Each mRNA value is normalized to GAPDH mRNA expression from the same sample. Each data point represents one individual and the black lines represent the median and interquartile range in each group. $P$-values were calculated using Mann-Whitney U-test (two groups) or Kruskal-Wallis (more than two groups) tests followed by Dunn's multiple comparison tests. (c) Correlation between the maximum eosinophil number per hpf and periostin mRNA expression in active EE only is shown. $P$-value and $r$ were calculated using Spearman correlation test. (d) Periostin expression in active EE patients ( $\geqslant 24$ eosinophils/hpf), patients with an intermediate phenotype ( $1 \geqslant 10$ and $11 \geqslant 23$ eosinophils/hpf), inactive EE patients ( 0 eosinophil/hpf), and normal patients $(0 \geqslant 1$ eosinophils/ hpf). $P$-values were calculated using Kruskal-Wallis test followed by Dunn's multiple comparison tests.

Periostin is a $90-\mathrm{kDa}$ secreted protein involved in cell adhesion, but otherwise of relatively unknown function. Periostin contains four repetitive fasciclin domains that are similar to insect fasciclin I, which is involved in neuronal cell-cell adhesion. ${ }^{17}$ Periostin has a dynamic expression profile in both the developing heart and in adult tissue where it is induced during active remodeling or active stress. ${ }^{16,18,19}$ Periostin is almost exclusively expressed by fibroblasts or cells that adopt fibroblast-like characteristics following injury. As a secreted protein associated with areas of fibrosis, periostin directly interacts with other ECM proteins, such as fibronectin, tenascin-C, collagen, and heparin. ${ }^{15}$ Periostin is a ligand for select integrins including $\alpha \mathrm{V} \beta 3, \alpha \mathrm{V} \beta 5$, and $\alpha 6 \beta 4,{ }^{20}$ where it can affect the ability of cells (fibroblasts or malignant cells) to migrate and/or undergo a mesenchymal transformation in select tissues. Interestingly, these same integrins $(\alpha \mathrm{V} \beta 3$ and $\alpha \mathrm{V} \beta 5)$ are implicated in receptor-mediated apoptotic eosinophil engulfment by human airway epithelial cells. ${ }^{21}$

Of note, a recent study has shown that mechanical stretch, a phenomenon that may occur in the thickened esophagus of EE patients, ${ }^{22-24}$ increases periostin expression in cardiac myocytes and fibroblasts. ${ }^{25}$ Recently generated periostin-null mice have revealed a role for periostin in cardiac myocyte and fibroblast function, particularly in the tissue remodeling response. ${ }^{3}$ Furthermore, extracellular periostin has been shown to induce proliferation of cardiomyocytes following cardiac injury. ${ }^{16}$ Taken together, these findings prompted us to test the role of periostin in EE, as this disease is characterized by marked tissue remodeling (e.g., fibrosis), hyperplasia of the cells in contact with the ECM (epithelial cells), and tissue dysfunction (dysmotility). ${ }^{5,6}$ Our results define a novel role for periostin in promoting eosinophil accumulation in vitro and in vivo.

\section{RESULTS}

\section{Periostin expression in EE}

Global quantitative microarray analysis revealed that periostin mRNA expression was significantly increased in EE. ${ }^{14}$ Within the EE transcript signature, periostin mRNA was increased 46-fold compared with biopsies from normal (NL) control individuals. ${ }^{14}$ Using real-time PCR analysis, a 35-fold increase in periostin mRNA was observed in EE patients $(0.141 \pm 0.122$; mean \pm s.d.) compared with NL individuals $(0.0043 \pm 0.0034)$ (Figure 1a). Of note, among the active EE patients, we did not find any significant difference in periostin expression 
a

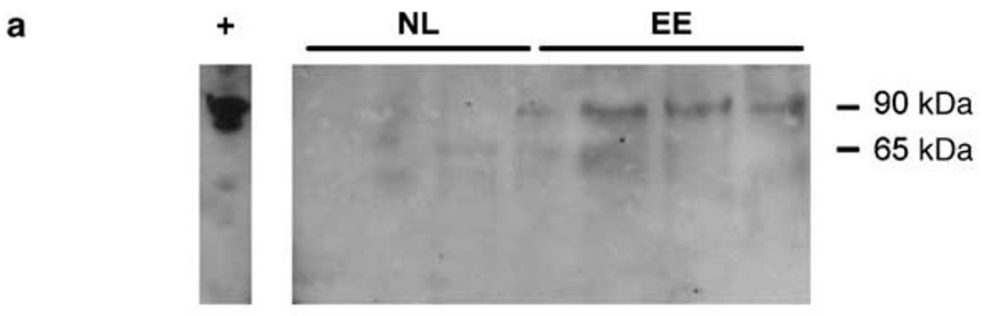

NL

EE
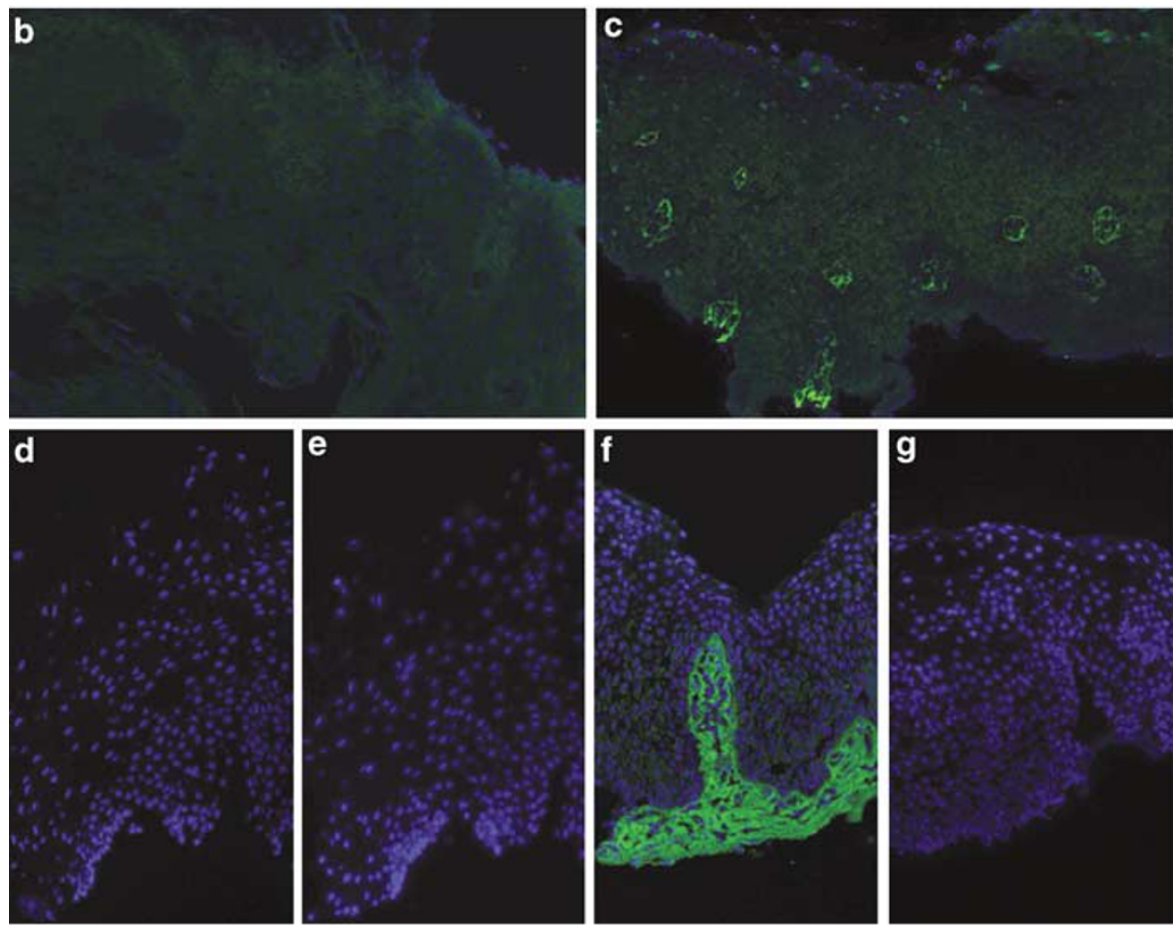

Figure 2 Periostin protein expression in esophageal biopsies of normal (NL) individuals and eosinophilic esophagitis (EE) patients. Esophageal biopsies from NL and EE patients were subjected to western blot, using (a) the recombinant human periostin (100 ng) as a positive control (+) and (b-g) immunofluorescence using a commercial rabbit anti-human periostin antibody. (b, d, e) NL patient biopsies and (c, $\mathbf{f}, \mathbf{g})$ EE patient biopsies were stained using $(\mathbf{b}, \mathbf{c}, \mathbf{d}, \mathbf{f})$ an anti-periostin antibody or $(\mathbf{e}, \mathbf{g})$ the normal rabbit control. (b, $\mathbf{c})$ Cross-sections of papillae and (d, $\mathbf{f})$ transverse sections of papillae are shown. Immunofluorescence results are representative of at least five NL and five EE patient biopsies.

between the allergic $(0.286 \pm 0.844)$ and non-allergic patients $(0.0440 \pm 0.0508)$ (Figure 1b). Interestingly, a significant correlation (Spearman $r=0.6375, P<0.0001, n=135$ ) was observed between periostin and eosinophil levels in esophageal biopsies (Figure 1c). Additionally, patients with active disease ( $\geqslant 24$ eosinophils per high power field(hpf)) have a significantly higher periostin expression $(P<0.001)$ than EE patients partially in remission (with $1 \geqslant 10$ eosinophils/hpf) or patients in complete remission (0 eosinophil/hpf). Western blot analysis of protein extracts from NL and EE esophageal biopsies revealed an increase of a protein band of $\sim 90 \mathrm{kDa}$ consistent with periostin protein (Figure 2a). In some samples, a faint $65 \mathrm{kDa}$ band was observed, most likely corresponding to the sliced variant periostin-like factor ${ }^{26-28}$ or a degradation product of periostin.

To localize periostin protein in the esophageal tissue, we performed immunofluorescence staining using a polyclonal rabbit anti-human periostin antibody. As shown in Figure 2c, periostin protein was expressed in the lamina propria of the esophagus of EE patients. The staining intensity was higher in EE biopsies than in NL biopsies, as shown in Figure $\mathbf{2 b}$. No signal was found when using a control antibody in EE biopsies (Figure 2e). Taken together, these results demonstrate that periostin is highly overexpressed in EE patients and accumulates in the underlying lamina propria.

\section{IL-13 and TGF $\beta$ induce periostin expression in vitro}

Interleukin-13 and TGF $\beta$ have been shown to be overexpressed in the esophagus of EE patients. ${ }^{5,13,29}$ We investigated if periostin was induced directly by these cytokines in primary esophageal cultures. Primary fibroblasts from the human esophagus were stimulated with $0,1,10$, and $100 \mathrm{ng} \mathrm{ml}^{-1}$ of IL-13. Periostin expression was increased in a dose-dependent manner in IL-13stimulated cells. A $295 \pm 138$-fold and a $4865 \pm 236$-fold increase (fold increase \pm s.d.) was observed following IL-13 stimulation (10 and $100 \mathrm{ng} \mathrm{ml}^{-1}$, respectively). We also tested if TGF $\beta$ had an additive or synergistic effect with IL-13. Notably, TGF $\beta$ induced periostin in fibroblasts (107 \pm 102 -fold increase) and no significant synergistic or additive effect was observed when the cells were treated with both IL-13 (100 $\left.\mathrm{ng} \mathrm{ml}^{-1}\right)$ and TGF $\beta(6700$ fold \pm 1849$)$ (Figure 3a). In contrast, TGF $\beta$ alone $\left(10 \mathrm{ng} \mathrm{ml}^{-1}\right)$ 

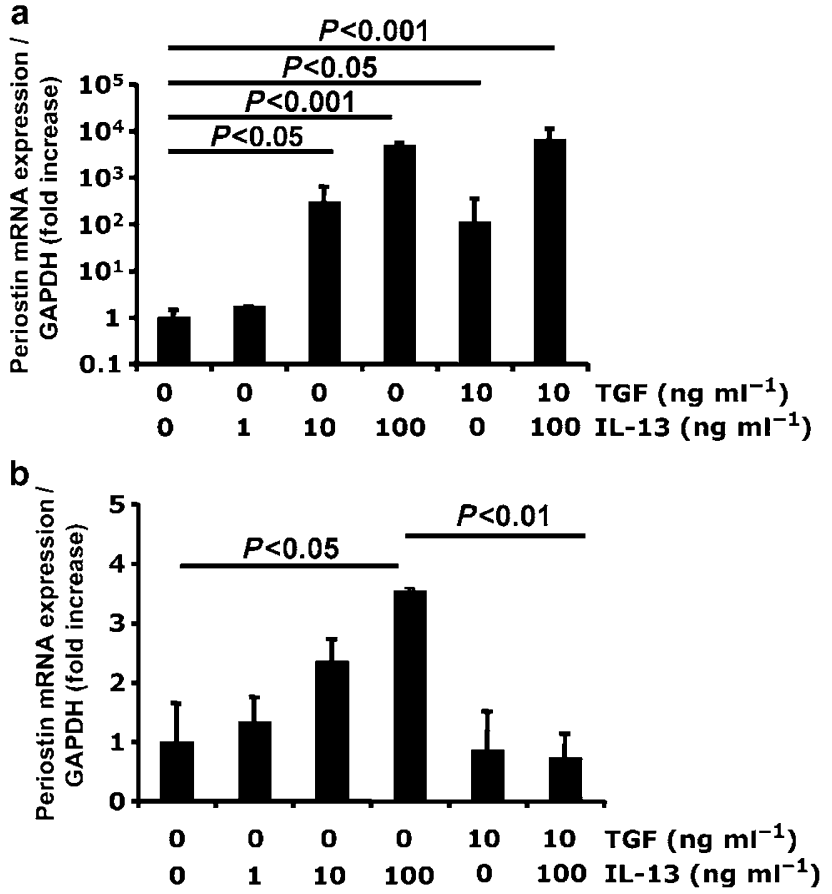

Figure 3 Periostin expression following interleukin (IL)-13 and transforming growth factor- $\beta$ (TGF $\beta$ ) stimulation in esophageal primary epithelial and fibroblast cells. (a) Human primary fibroblasts and (b) esophageal epithelial cells were stimulated for $24 \mathrm{~h}$ with IL-13 $\left(0,1,10,100 \mathrm{ng} \mathrm{ml}^{-1}\right)$ and TGF $\beta\left(10 \mathrm{ng} \mathrm{ml}^{-1}\right)$. Periostin RNA expression was quantified using real-time PCR. $P$-values were calculated using the Student's $t$-test. These experiments are representative of at least three independent experiments performed in duplicate or triplicate. Results are mean \pm s.d.

did not stimulate epithelial cell production of periostin (Figure 3b). A relatively modest increase in periostin expression was observed in IL-13-stimulated epithelial cells at $100 \mathrm{ng} \mathrm{ml}^{-1}$ (3.53 \pm 0.044 -fold increase) (Figure $3 b$ ). When epithelial cells were treated with both IL-13 and TGF $\beta$, a decrease of periostin mRNA expression was observed compared with IL-13 treatment alone $(P<0.05)$. These results indicate that periostin is modestly induced by IL-13 in primary epithelial cells and is strongly induced by TGF $\beta$ and IL-13 in primary esophageal fibroblasts.

\section{Eosinophil accumulation in periostin-deficient mice}

To test the role of periostin in the induction of tissue eosinophilia in vivo, we induced allergic eosinophilic inflammation in periostin gene-targeted mice by repeated intranasal exposure to the allergenic extracts of $A$. fumigatus. This protocol induces simultaneous lung and esophageal inflammation; ${ }^{30}$ we first focused on lung inflammatory cells in the bronchoalveolar lavage fluid (BALF) of wild-type and periostin-deficient mice. The total number of cells was significantly increased $(P<0.05)$ in allergen-challenged wild-type $\left(40 \pm 21 \times 10^{4}\right)$ and periostindeficient groups compared with saline-challenged wild-type $\left(2.4 \pm 0.12 \times 10^{4}\right)$ and periostin-deficient $\left(2.05 \pm 0.9 \times 10^{4}\right)$ control groups (Figure 4a). Differential cell analysis revealed a significant $(P<0.05)$ and specific decrease (threefold) in eosinophil numbers in allergen-challenged periostin-deficient mice $\left(8.2 \pm 1.9 \times 10^{4}\right)$ compared with wild-type mice $\left(25 \pm 14 \times 10^{4}\right)$ (Figure $4 \mathbf{b}$ ). Notably, the levels of neutrophils and lymphocytes were not significantly different between allergen-challenged wild-type and periostin-deficient mice (Figure $4 \mathbf{b}$ ).

Of note, no significant differences in eotaxin-1 or eotaxin-2 protein levels in the BALF or lung mucus (periodic acid-Schiff) staining were observed between allergen-challenged wild-type and periostin-deficient mice (data not shown).

Eosinophils in the esophagus were quantified in wild-type and periostin-deficient mice challenged with either saline or allergen. The level of eosinophils in allergen-challenged wildtype mice $\left(36 \pm 16\right.$ eosinophils $\left.\mathrm{mm}^{-2}\right)$ was significantly increased (10-fold; $P<0.05)$ compared with saline-challenged wild-type mice $\left(3.5 \pm 3.9\right.$ eosinophils $\left.\mathrm{mm}^{-2}\right)$ (Figure 4c). A significant reduction $(72 \%, P<0.05)$ in esophageal eosinophil numbers was observed in allergen-challenged periostin-deficient mice $\left(9.9 \pm 7.4\right.$ eosinophils $\mathrm{mm}^{-2}$ ) compared with allergen-challenged wild-type mice (Figure 4c).

As eosinophil recruitment was impaired in the lungs and the esophagus, we analyzed the number of eosinophils in the blood of these mice. We found a significant increase of eosinophils in the blood of allergen-challenged wild-type $\left(18 \pm 6 \times 10^{4}\right)$ and periostin-deficient mice $\left(32 \pm 5 \times 10^{4}\right)$ compared to saline-challenged mice $\left(6 \pm 1 \times 10^{4}\right.$ and $\left.6 \pm 1.4 \times 10^{4}\right)$ (Figure $4 d$ ). Interestingly, a significant increase (1.7-fold) in blood eosinophilia was observed in allergen-challenged periostin-deficient mice compared with allergen-challenged wild-type mice. Baseline blood eosinophil levels were not significantly different between naïve wild-type and periostin-deficient mice (data not shown).

\section{Periostin modifies eosinophil adhesion}

We aimed to test if periostin had a direct effect on eosinophil function. To understand the role of periostin on eosinophil accumulation in the tissues, we tested the role of periostin on eosinophil transmigration, chemoattraction, and adhesion to the ECM. We examined periostin-deficient eosinophils to avoid possible effects of previous periostin exposure in the serum. Direct exposure of eosinophils to periostin (top well) significantly decreased eotaxin-2 $\left(10 \mathrm{ng} \mathrm{ml}^{-1}\right)$-induced transmigration $\left(22.8 \pm 1.6 \times 10^{3}\right.$ vs. $9.3 \pm 3.7 \times 10^{3}$ eosinophils, $\left.P<0.05\right)$ (Figure 5a), whereas a gradient (bottom well) lead to a moderate but nonsignificant decrease. To test if the decreased chemoattraction was dependent upon epithelial cells, chemotaxis through a bare transwell membrane was performed. A similar, profound decrease in eosinophil chemoattraction in response to eotaxin- 2 was still observed in the presence of periostin ( $23.3 \pm 2.6$ vs. $7.8 \pm 0.6 \times 10^{3}$ eosinophils, respectively, $P<0.01$ ) (Figure 5b). Interestingly, periostin was able to significantly $(P<0.05)$ decrease eotaxin2 -induced eosinophil chemotaxis when eotaxin-2 was used at a higher concentration $\left(100 \mathrm{ng} \mathrm{ml}^{-1}\right.$ ) (data not shown). Finally, we investigated the role of periostin on eosinophil adhesion to the ECM component fibronectin. Periostin dose-dependently increased eosinophil adhesion to fibronectin $\left(12.3 \pm 1.8 \times 10^{3}\right.$ eosinophils) compared with saline $\left(2.1 \pm 0.8 \times 10^{3}\right.$ eosinophils, $P<0.005)$ (Figure 5c). Taken together, these results demonstrate that periostin increases eosinophil adhesion in vitro. 

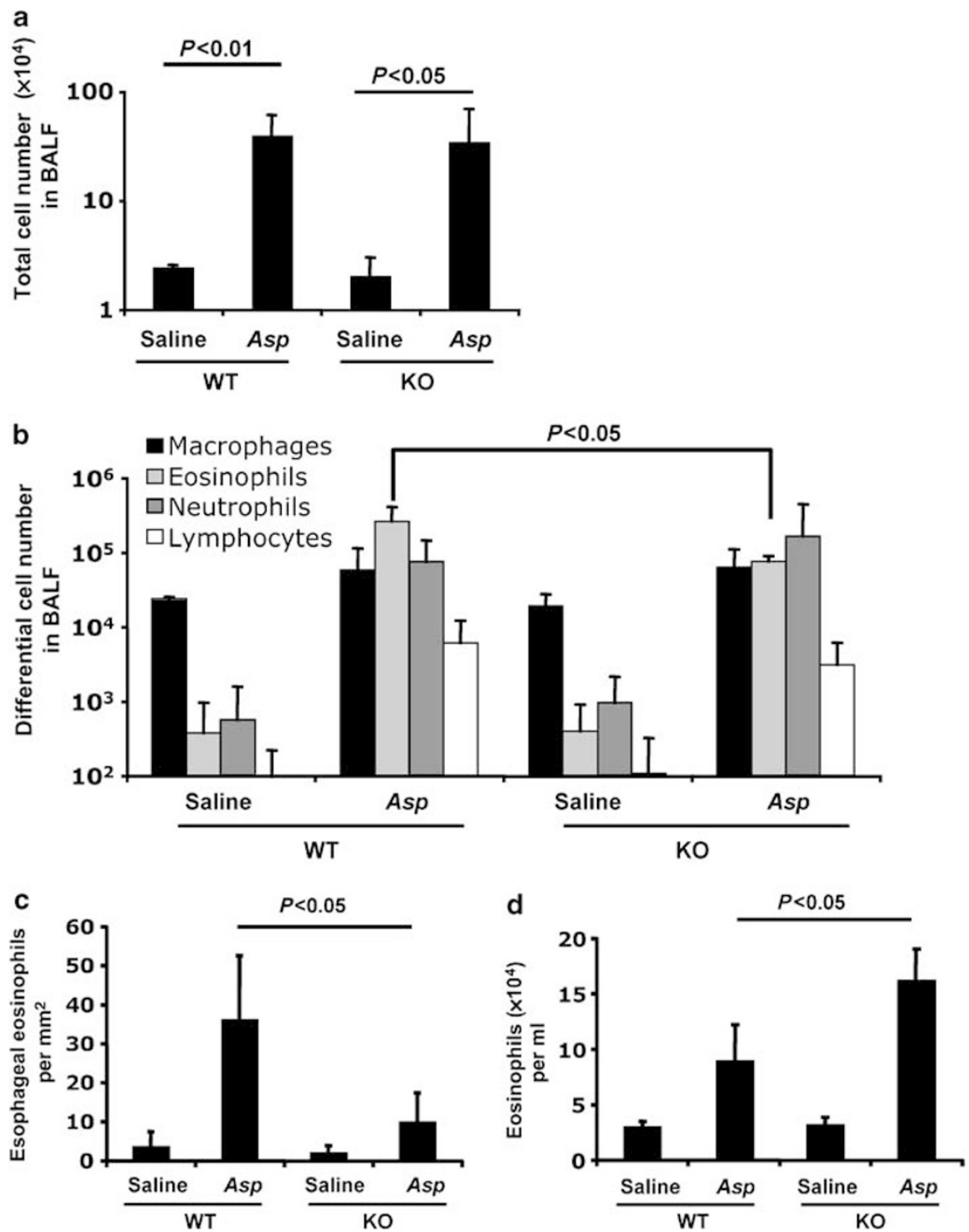

Figure 4 Effect of periostin deficiency on allergen-induced airway and esophageal eosinophilic inflammation. Mice were intranasally challenged three times a week for 3 weeks with Aspergilus fumigatis (Asp) extract or saline solution. Bronchoalveolar lavage fluid (BALF) cells were collected and analyzed $24 \mathrm{~h}$ after the last intranasal exposure. (a) The total cell numbers are shown. (b) Total BALF numbers of macrophages, eosinophils, neutrophils, and lymphocytes were quantified. (c) Density of eosinophils in the esophagus is shown and expressed as eosinophils $/ \mathrm{mm}^{2}$. (d) Total number of eosinophils were evaluated in the whole blood and are expressed as cells per $\mathrm{ml}$ of blood. In this representative experiment, data are expressed as mean \pm s.d.; $n=4-7$ mice.

\section{DISCUSSION}

We investigated the expression, regulation, and role of periostin in Thelper type 2 responses with particular focus on eosinophil accumulation in the tissues. We demonstrate that periostin is markedly upregulated in EE patients with high expression in the esophageal papillae. Notably, levels of periostin strongly correlated with esophageal eosinophil levels. Furthermore, we demonstrated that IL-13 and TGF $\beta$ increase periostin production in primary esophageal fibroblasts. To define the role of periostin in vivo, we subjected periostin-deficient mice to induction of experimental allergic responses in the lung and the esophagus. Notably, periostin-deficient mice developed reduced eosinophilic infiltration in the esophageal mucosa and lung compared with wild-type mice. Mechanistic analysis demonstrated that periostin directly increases eosinophil adhesion in vitro.

Interleukin-13 and TGF $\beta$ have been shown to be upregulated in EE patient biopsies compared with NL individuals. ${ }^{5,14} \mathrm{We}$ thus investigated the propensity of IL-13 and/or TGF $\beta$ to induce periostin expression. Using esophageal primary cultures of fibroblasts and epithelial cells, we uncovered that IL-13 was able to induce periostin expression in fibroblasts and, more modestly, in epithelial cells. In vivo and in vitro, periostin has been shown to be induced by phosphoinositide kinase 3 and STAT $6,{ }^{15,31}$ which are both involved in IL-13 signaling. ${ }^{32}$ Interestingly, the protein SMAD2/3 is activated in EE patients. ${ }^{5}$ Of note, TGF $\beta$ has been shown to be expressed by eosinophils in EE, 
a Transmigration

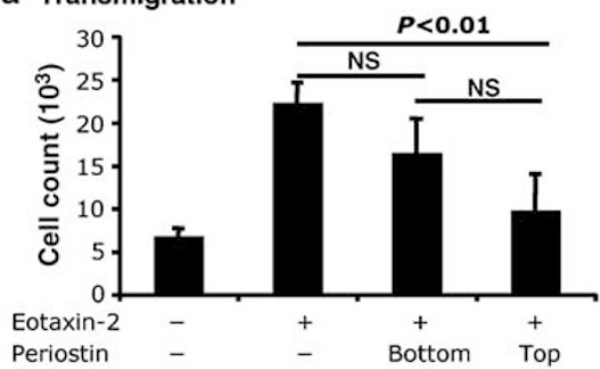

b Chemotaxis

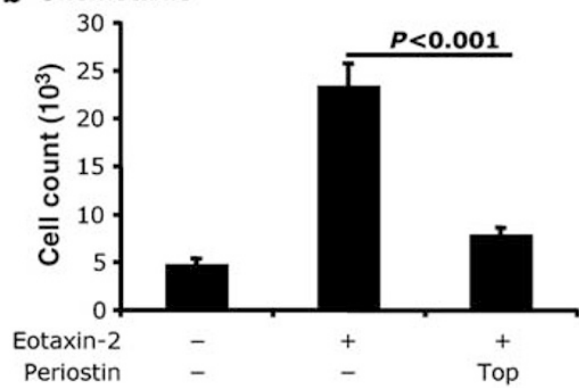

C Adhesion
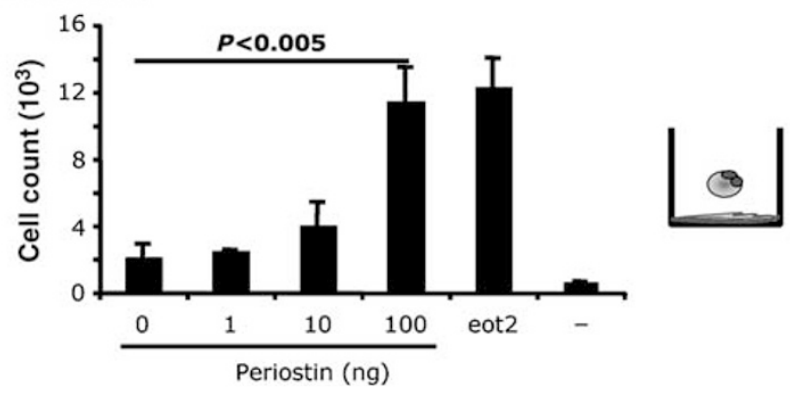

Figure 5 Effect of periostin on eosinophil transmigration, chemotaxis, and adhesion. Eosinophils were subjected to transmigration, chemotaxis, and adhesion assays. (a) Cells were subjected to transmigration through a monolayer of esophageal epithelial cells in the presence of an eotaxin$2\left(10 \mathrm{n} \mathrm{ml}^{-1}\right)$ in the top or bottom well. Discombe positive cells in the bottom wells were counted after $3 \mathrm{~h}$ of incubation. (b) Eosinophils were subjected to chemotaxis through $3 \mu \mathrm{m}$ pores. Periostin (100 ng) was added in the top wells and cells were subjected to an eotaxin-2 gradient (placed in the bottom wells) for $3 \mathrm{~h}$ before cells were counted in the bottom well. (c) The effect of periostin (0-100 ng) was tested on eosinophil adhesion to a fibronectin-coated plate. Adherent cells were quantified after $30 \mathrm{~min}$ incubation with calcein AM. Adhesion to fibronectin in the presence of eotaxin-2 $\left(10 \mathrm{ng} \mathrm{ml}^{-1}\right)$ was used as a positive control and adhesion on bare plastic was the negative control (-).

a process linked with the tissue remodeling that occurs in $\mathrm{T}$ helper type 2 inflammation. ${ }^{5}$

Eosinophil accumulation in the lung and the esophagus was decreased in allergen-challenged periostin-deficient mice compared with wild-type mice. The combined findings of increased eosinophil blood levels following allergen challenge of periostin-deficient mice and the ability of periostin to increase eosinophil adhesion suggest that the decreased tissue eosinophil level was due to an impaired chemotactic response. These results extend those of recent publications that reported that periostin is upregulated in lung epithelial cells by IL-13 and in the lung of allergen-challenged mice ${ }^{15}$ by demonstrating a direct role for periostin in promoting allergen-induced tissue eosinophilia. Our results support structural similarities between periostin and the fasciclin family of molecules that have been shown to be involved in cellular adhesion and migration. ${ }^{20,33-35}$ To the best of our knowledge, our findings are the first to directly link periostin with leukocyte function. Interestingly, both the eosinophil chemoattractant eotaxin-3 and periostin have been shown to be overexpressed following vascular injury. ${ }^{36,37}$ It has been demonstrated that eotaxin-3 is the single eosinophil chemoattractant induced in EE; its expression is localized in the epithelial layer. ${ }^{14}$ Based on these collective results, we propose a model in which the co-expression of both eotaxin-3 and periostin cooperate to induce eosinophil infiltration. Perhaps eotaxin-3 attracts eosinophils in the epithelium, and periostin increases adhesion of eosinophils from the vessel to the lamina propria. Some authors have suggested that the inhibition of periostin might become a new therapeutic target for the treatment of heart failure. ${ }^{38}$ Our study extends the involvement of periostin in heart remodeling responses to a more generalized response to diverse tissue injury signals. We propose that inducible periostin has dramatic effects on regulating eosinophil recruitment into allergic inflammatory foci; as such, these results highlight the potential therapeutic effect of antiperiostin in allergic mucosal inflammation.

\section{METHODS}

Patient biopsies. Patient biopsies, collected from the distal esophagus $(<5 \mathrm{~cm}$ from the lower esophageal sphincter), were submerged in formalin for routine pathological analysis with hematoxylin-and-eosin staining. Diagnosis was established based on the maximum eosinophil count per hpf $(\times 400)$ and basal layer expansion according to established criteria. ${ }^{39-41}$ Three slides per patients were counted. Each slide contained 1-4 distal esophageal biopsies and 2-5 sections. The maximum number of eosinophils/hpf on any of these biopsies, slides, or sections was used. Normal patients were defined as having 0 eosinophils/hpf and no basal layer expansion. EE patients were defined as having $\geqslant 24$ eosinophils/hpf and extensive basal layer hyperplasia (expansion to approximately $>1 / 3$ of epithelium). Allergy was defined as any history of allergic diseases (atopic rhinitis, atopic dermatitis, or asthma). Activity of the disease was defined only by the number of eosinophils in the biopsy regardless of the diet or treatment. Active EE was defined as $\geqslant 24$ eosinophils/hpf; and inactive as 0 eosinophil/hpf. This study was approved by the Institutional Review Board of the Cincinnati Children's Hospital Medical Center.

Quantitative PCR. The RNA samples (500 ng) were subjected to reverse transcription analysis using Bioscript reverse transcriptase (Bio-Rad, Hercules, CA) according to the manufacturer's instructions. Human and murine periostin, eotaxin-1, and eotaxin- 2 were quantified by real-time PCR using IQ5 (Bio-Rad). Results were then normalized to human GAPDH or mouse HPRT amplified from the same cDNA mix and expressed as fold induction compared with the controls. cDNA were amplified using the following primers: hperiostin: gtctttgagacgctggaa gg and agatccgtgaaggtggtttg; mperiostin: gtgtttgaggaccatggaagg and aggtcggtgaaagtggtttg; mEotaxin-1: cccaacacactactgaagagcta caa and tttgcccaacctggtcttg; mEotaxin-2 (280 bp): tgtgaccatcccctcat atcttgc and aaacctcggtgctattgccacg; hGAPDH: tggaaatcccatcaccatct and gtcttctgggtggcagtgat; mHPRT: gtaatgatcagtcaacgggggac and ccagcaagcttg caaccttaacca.

Western blot. Biopsy lysates were extracted as described previously ${ }^{14}$ and subjected to western blot analysis. Protein $(50 \mu \mathrm{g})$ was subjected to 
electrophoresis in glycine-Tris gels, transferred to nitrocellulose membranes. The membrane was stained with Ponceau red solution (Sigma, St Louis, MO) to assess loading control. After blocking in Tris-buffered saline/milk 5\%, the membrane was incubated with the rabbit anti-human periostin $\mathrm{Ab}$ (Abcam, Cambridge, MA) at 1/8,000 dilution followed by an anti-rabbit IgG HRP antibody $(1 / 2,500)$; enhanced chemiluminescent was then used for autoradiography.

Immunofluorescence. For immunofluorescence microscopy, slidemounted cryosections were air-dried and acetone-fixed, washed in phosphate-buffered saline (PBS), treated with a blocking solution containing $2 \%$ goat serum, and then incubated $\left(18 \mathrm{~h}\right.$ at $\left.4^{\circ} \mathrm{C}\right)$ with diluted (1/500), rabbit anti-human periostin (Abcam) primary antibody. Sections were then washed with PBS and incubated (1:200 dilution, $30 \mathrm{~min}$ at $25^{\circ} \mathrm{C}$ ) with Alexafluor 488 -labeled goat anti-rabbit secondary antibody (Molecular Probes/Invitrogen, Carlsbad, CA). After washing with PBS, slides were coverslipped using antifade medium containing 4',6-diamidino-2-phenylindole (Prolong Gold; Molecular Probes/Invitrogen) and photographed using an RT Slider digital camera (Diagnostic Instruments, Sterling Heights, MI).

Experimental modeling of allergic eosinophilic inflammation in vivo. Four- to eight-week-old periostin-deficient mice in 129 SVEV background and littermate wild-type controls ${ }^{3}$ were kept in a specific pathogen-free environment. All procedures were performed in accordance with the ethical guidelines in the Guide for the Care and Use of Laboratory Animals of the Institutional Animal Care and Use Committee approved by the Veterinary Services Department of the Cincinnati Children's Hospital Medical Center Research Foundation. Briefly, mice were anesthetized with Isoflurane (IsoFlo, Abbott Laboratories, North Chicago, IL) and were subjected to intranasal challenges (three times a week for 3 weeks) with $50 \mu \mathrm{l}$ of Aspergillus fumigatus extract $\left(1 \mathrm{mg} \mathrm{ml}^{-1}\right)$ or $50 \mu$ l of saline alone, as reported previously. ${ }^{30}$

Blood eosinophil counts. Eosinophil count was measured by Discombe's analysis using $5 \mu \mathrm{l}$ of blood obtained from the lateral tail vein as described previously. ${ }^{42}$ Positively stained eosinophils were counted by hemacytometry by light microscopy.

BALF collection and analysis. Mice were killed by carbon dioxide inhalation $24 \mathrm{~h}$ following the previous Aspergillus fumigatus challenge. Immediately thereafter, the trachea was cannulated and the lungs were lavaged twice with $1 \mathrm{ml}$ PBS containing $1 \%$ fetal calf serum and $0.5 \mathrm{mmoll}^{-1}$ of EDTA. Lysis of red blood cells was carried out using RBC lysis buffer (Sigma) according to the manufacturer's recommendations. The recovered BALF was centrifuged and the cell pellets were resuspended in $200 \mu \mathrm{l}$ of PBS/1\% fetal calf serum. Total cell numbers per lung were counted with a hemacytometer. Differential cell counts were determined from cytospins stained with Giemsa-Diff-Quick (Dade Diagnostics of P.R., Aguada, PR).

Histological analysis. Following BALF collection, the lung and esophagus were fixed in $4 \%$ paraformaldehyde in phosphate buffer, $\mathrm{pH} 7.4$, and embedded in paraffin. Lung sections $(2-3 \mu \mathrm{m})$ were stained with periodic acid-Schiff for goblet cell metaplasia analysis. Histologic mucus index (HMI) provides a percentage of epithelial cells that are periodic acid-Schiff positive. Esophageal sections were also immunostained with a rat anti-mouse eosinophil major basic protein (anti-MBP). Briefly, endogenous peroxidases in the tissues were quenched with $0.3 \%$ hydrogen peroxide in methanol followed by pepsin digestion for $5 \mathrm{~min}$ and by nonspecific protein blocking with normal goat serum for $30 \mathrm{~min}$ at room temperature. Tissue sections were then incubated with rabbit anti-MBP (a kind gift from Dr James Lee, Mayo Clinic, Scottsdale, AZ) $(1: 6,000)$ for $1 \mathrm{~h}$ at $4^{\circ} \mathrm{C}$, followed by a 1:1,000 dilution of biotinylated goat anti-rat IgG secondary antibody for $30 \mathrm{~min}$ at room temperature. Negative controls were assessed by replacing the primary antibody with an isotype-matched control antibody to check endogenous biotin and peroxidase activity.
Then avidin-peroxidase complex (Vector Laboratories, Burlingame, CA) was used for $30 \mathrm{~min}$. Quantification of the immunoreactive cells was carried out by using a video-assistant integrated computer software program (Image Pro Plus 4.1; Media Cytometrics, Silver Spring, MD). The eosinophil levels are expressed as cells per $\mathrm{mm}^{2}$ (ref. 10).

Chemotaxis, transmigration, and adhesion assays. To obtain a large quantity of eosinophils, we used the spleen cells from CD2-IL-5 transgenic mice, which are in a BALB/c background. To avoid the potential bias of periostin highly present in the serum, these mice were crossed with periostin knockout mice, which are in an SVEV129 background. The spleen from IL-5 tg mice, deficient for the periostin gene (BALB/c/SVEV129 mixed background) were lysed in $4 \mathrm{ml}$ of $\mathrm{H}_{2} \mathrm{O}$ for $30 \mathrm{~s}$ to $1 \mathrm{~min}$, then neutralized with $400 \mu \mathrm{l}$ of $10 \times$ PBS. Lysed lymphocytes were discarded, and the cells were centrifuged and resuspended in $1 \times$ HBSS. For transmigration, $3 \mu \mathrm{m}$ transwells (Costar/Corning, Fisher Scientific Co., Pittsburgh, PA) were incubated overnight with RPMI $10 \%$ fetal calf serum. One million cells per condition were added to the top of the transwells and subjected to an eotaxin-2 gradient $\left(10 \mathrm{ng} \mathrm{ml}^{-1}\right)$ for $3 \mathrm{~h}$ as reported. ${ }^{42}$ Periostin (100 ng) was either added to the bottom or to the top of the transwell. For transmigration, TE7 cells ${ }^{13}$ were previously grown on the transwell membrane. Nonadherent eosinophils were counted at the bottom well using Discombe's staining. For adhesion assays, ELISA plates 3690 (Costar) were coated with fibronectin $\left(1 \mu \mathrm{g} \mathrm{ml}^{-1}\right)$ for a minimum of $3 \mathrm{~h}$ and 30,000 cells were incubated for $3 \mathrm{~h}$ with or without periostin $\left(0-1,000 \mathrm{ng} \mathrm{ml}^{-1}\right)$ in HBSS. Adhesion was assessed after incubation with Calcein AM for a minimum of $30 \mathrm{~min}$ and the IQ5 (Bio-Rad) fluorescence plate-reader.

Statistical analysis. For all cell counts, stained slides were analyzed randomly and in a blinded fashion. The nonparametric Mann-Whitney $U$-test was employed for comparison of data between two groups, and Krustal-Wallis for comparison of more then two groups. Parametric data were compared using $t$-tests or analysis of variance. Values are reported as mean \pm s.d. $P$-values $<0.05$ were considered statistically significant.

\section{ACKNOWLEDGMENTS}

This work was funded in part by the American Heart Association 0625296B (CB), the Thrasher Research Fund NR-0014 (CB), the NIH AI070235, Al45898, and DK076893 (MER), the Food Allergy and Anaphylaxis Network (FAAN) (MER), Campaign Urging Research for Eosinophil Disorders (CURED), the Buckeye Foundation (MER), the Food Allergy Project (MER), and the Core of the Digestive Disease Research Core Center (DK0789392). We thank Dr James Lee (Mayo Clinic, Scottsdale, AZ) for providing the anti-MBP antibody. We also thank everybody in the Cincinnati Center for Eosinophilic Disorders (CCED), more particularly Sean Jameson, Bridget Buckmeier, Annette Arhens, and Margaret Palazzolo.

\section{DISCLOSURE}

Dr. Rothenberg is a consultant and has received research funds from Merck and Ception Therapeutics.

(C) 2008 Society for Mucosal Immunology

\section{REFERENCES}

1. Spinale, F.G. Myocardial matrix remodeling and the matrix metalloproteinases: influence on cardiac form and function. Physiol. Rev 87, 1285-1342 (2007)

2. Walker, G.A., Masters, K.S., Shah, D.N., Anseth, K.S. \& Leinwand, L.A. Valvular myofibroblast activation by transforming growth factor-beta: implications for pathological extracellular matrix remodeling in heart valve disease. Circ. Res. 95, 253-260 (2004).

3. Oka, T. et al. Genetic manipulation of periostin expression reveals a role in cardiac hypertrophy and ventricular remodeling. Circ. Res. 101, 313-321 (2007).

4. Elias, J.A., Zhu, Z., Chupp, G. \& Homer, R.J. Airway remodeling in asthma. J. Clin. Invest. 104, 1001-1006 (1999).

5. Aceves, S.S., Newbury, R.O., Dohil, R., Bastian, J.F. \& Broide, D.H. Esophageal remodeling in pediatric eosinophilic esophagitis. J. Allergy Clin. Immunol. 119, 206-212 (2007). 
6. Mishra, A. et al. Esophageal remodeling develops as a consequence of tissue specific IL-5-induced eosinophilia. Gastroenterology 134, 204-214 (2008).

7. Noel, R.J. \& Rothenberg, M.E. Eosinophilic esophagitis. Curr. Opin. Pediatr. 17, 690-694 (2005).

8. Siafakas, C.G., Ryan, C.K., Brown, M.R. \& Miller, T.L. Multiple esophageal rings: an association with eosinophilic esophagitis: case report and review of the literature. Am. J. Gastroenterol. 95, 1572-1575 (2000).

9. Mishra, A. \& Rothenberg, M.E. Intratracheal IL-13 induces eosinophilic esophagitis by an IL-5, eotaxin-1, and STAT6-dependent mechanism. Gastroenterology 125, 1419-1427 (2003).

10. Blanchard, C. et al. Inhibition of human interleukin-13-induced respiratory and oesophageal inflammation by anti-human-interleukin-13 antibody (CAT-354). Clin. Exp. Allergy 35, 1096-1103 (2005).

11. Schmid-Grendelmeier, P. et al. Eosinophils express functional IL-13 in eosinophilic inflammatory diseases. J. Immunol. 169, 1021-1027 (2002).

12. Straumann, A., Bauer, M., Fischer, B., Blaser, K. \& Simon, H.U. Idiopathic eosinophilic esophagitis is associated with a $\mathrm{T}(\mathrm{H}) 2$-type allergic inflammatory response. J. Allergy Clin. Immunol. 108, 954-961 (2001).

13. Blanchard, C. et al. IL-13 involvement in eosinophilic esophagitis: transcriptome analysis and reversibility with glucocorticoids. J. Allergy Clin. Immunol. 120, 1292-1300 (2007).

14. Blanchard, C. et al. Eotaxin-3 and a uniquely conserved gene-expression profile in eosinophilic esophagitis. J. Clin. Invest. 116, 536-547 (2006).

15. Takayama, G. et al. Periostin: a novel component of subepithelial fibrosis of bronchial asthma downstream of IL-4 and IL-13 signals. J. Allergy Clin. Immunol. 118, 98-104 (2006).

16. Kuhn, B. et al. Periostin induces proliferation of differentiated cardiomyocytes and promotes cardiac repair. Nat. Med. 13, 962-969 (2007).

17. Hortsch, M. \& Goodman, C.S. Drosophila fasciclin I, a neural cell adhesion molecule, has a phosphatidylinositol lipid membrane anchor that is developmentally regulated. J. Biol. Chem. 265, 15104-15109 (1990)

18. Katsuragi, N. et al. Periostin as a novel factor responsible for ventricular dilation. Circulation 110, 1806-1813 (2004)

19. Kruzynska-Frejtag, A., Machnicki, M., Rogers, R., Markwald, R.R. \& Conway, S.J. Periostin (an osteoblast-specific factor) is expressed within the embryonic mouse heart during valve formation. Mech. Dev. 103 183-188 (2001)

20. Gillan, L. et al. Periostin secreted by epithelial ovarian carcinoma is a ligand for alpha(V)beta(3) and alpha(V)beta(5) integrins and promotes cell motility. Cancer Res. 62, 5358-5364 (2002).

21. Sexton, D.W., Blaylock, M.G. \& Walsh, G.M. Human alveolar epithelial cells engulf apoptotic eosinophils by means of integrin- and phosphatidylserine receptor-dependent mechanisms: a process upregulated by dexamethasone. J. Allergy Clin. Immunol. 108, 962-969 (2001).

22. Cheung, K.M., Oliver, M.R., Cameron, D.J., Catto-Smith, A.G. \& Chow, C.W. Esophageal eosinophilia in children with dysphagia. J. Pediatr Gastroenterol. Nutr. 37, 498-503 (2003).

23. Black, D.D., Haggitt, R.C., Orenstein, S.R. \& Whitington, P.F. Esophagitis in infants. Morphometric histological diagnosis and correlation with measures of gastroesophageal reflux. Gastroenterology 98, 1408-1414 (1990).
24. Fox, V.L., Nurko, S. \& Furuta, G.T. Eosinophilic esophagitis: it's not just kid's stuff. Gastrointest. Endosc. 56, 260-270 (2002).

25. lekushi, K. et al. Novel mechanisms of valsartan on the treatment of acute myocardial infarction through inhibition of the antiadhesion molecule periostin. Hypertension 49, 1409-1414 (2007).

26. Litvin, J., Chen, X., Keleman, S., Zhu, S. \& Autieri, M. Expression and function of periostin-like factor in vascular smooth muscle cells. Am. J. Physiol. Cell Physiol. 292, C1672-C1680 (2007).

27. Litvin, J. et al. Periostin and periostin-like factor in the human heart: possible therapeutic targets. Cardiovasc. Pathol. 15, 24-32 (2006).

28. Litvin, J. et al. Expression and function of periostin-isoforms in bone. J. Cell Biochem. 92, 1044-1061 (2004).

29. Straumann, A. et al. Cytokine expression in healthy and inflamed mucosa: probing the role of eosinophils in the digestive tract. Inflamm. Bowel. Dis. 11, 720-726 (2005).

30. Mishra, A., Hogan, S.P., Brandt, E.B. \& Rothenberg, M.E. An etiological role for aeroallergens and eosinophils in experimental esophagitis. J. Clin. Invest. 107, 83-90 (2001).

31. Li, G. et al. Phosphatidylinositol-3-kinase signaling mediates vascular smooth muscle cell expression of periostin in vivo and in vitro. Atherosclerosis 188, 292-300 (2006).

32. Jiang, H., Harris, M.B. \& Rothman, P. IL-4/IL-13 signaling beyond JAK/ STAT. J. Allergy Clin. Immunol. 105, 1063-1070 (2000).

33. Horiuchi, K. et al. Identification and characterization of a novel protein, periostin, with restricted expression to periosteum and periodontal ligament and increased expression by transforming growth factor beta. J. Bone Miner Res. 14, 1239-1249 (1999).

34. Siriwardena, B.S. et al. Periostin is frequently overexpressed and enhances invasion and angiogenesis in oral cancer. Br. J. Cancer 95 1396-1403 (2006)

35. Bao, S. et al. Periostin potently promotes metastatic growth of colon cancer by augmenting cell survival via the Akt/PKB pathway. Cancer Cell 5, 329-339 (2004)

36. Lindner, V., Wang, Q., Conley, B.A., Friesel, R.E. \& Vary, C.P. Vascular injury induces expression of periostin: implications for vascular cell differentiation and migration. Arterioscler. Thromb. Vasc. Biol. 25, 77-83 (2005).

37. Kalomenidis, l. et al. Eotaxin-3 and interleukin-5 pleural fluid levels are associated with pleural fluid eosinophilia in post-coronary artery bypass grafting pleural effusions. Chest 127, 2094-2100 (2005).

38. Litvin, J., Zhu, S., Norris, R. \& Markwald, R. Periostin family of proteins: therapeutic targets for heart disease. Anat. Rec. A Discov. Mol. Cell Evol. Biol. 287, 1205-1212 (2005).

39. Ruchelli, E., Wenner, W., Voytek, T., Brown, K. \& Liacouras, C. Severity of esophageal eosinophilia predicts response to conventional gastroesophageal reflux therapy. Pediatr. Dev. Pathol. 2, 15-18 (1999).

40. Kelly, K.J. et al. Eosinophilic esophagitis attributed to gastroesophageal reflux: improvement with an amino acid-based formula. Gastroenterology 109, 1503-1512 (1995).

41. Sant'Anna, A.M., Rolland, S., Fournet, J.C., Yazbeck, S. \& Drouin, E. Eosinophilic esophagitis in children: symptoms, histology and $\mathrm{pH}$ probe results. J. Pediatr. Gastroenterol. Nutr. 39, 373-377 (2004).

42. Brandt, E.B. \& Rothenberg, M.E. Eosinophil levels in mice are significantly higher in small blood vessels than in large blood vessels. J. Allergy Clin. Immunol. 108, 142-143 (2001). 